\title{
The buck stops here
}

\section{Do we have free will, or are all of our choices predetermined?}

\author{
Freedom Evolves \\ by Daniel Dennett \\ Allen Lane: 2003.352 pp. $£ 20$ \\ Viking: 2003. \$24.95

\section{Melvin Konner}

The puzzle of free will is not something new. Intelligent people have always wondered how, if all is fated, or if an omniscient God can know all in advance, choice can be free. Even a child can see the problem: if God knows what I am going to do, how can my choice be meaningful? Theologians have answers to the child's question, of course, but none of them satisfies scientists.

The best answer, perhaps, is that God does not direct your choice but merely knows what you will do with it. This still leaves the paradox of predestination, but religious people who believe in an omniscient God cannot escape the subjective sense that they are making choices.

Scientists have a parallel, possibly more difficult, problem. Our minds, we believe, are instantiated in our brains, and our choices are at the end of a causal chain that includes environmental influences operating on a developmental process resulting from a coherent, hierarchically ordered set of at least 30,000 genes. This set of genes is in turn the result of natural selection operating imperfectly on previous sets of genes over several billion years. Behind those first modestly stable strings of nucleic acids were another ten billion years or so of physical and chemical events going back to the Big Bang, which I call Lumina.

Lumina's cause is indeterminate, but every single event that followed it, including my decision to write this review or yours to read it, has been in an important sense determined. Quantum indeterminacy is about what cannot in principle be known, but each step leading up to a choice involves so many quantum events that we can sum them statistically and ignore quantum indeterminacy. So my choice to write the review was determined by the time I answered the invitation. In what sense, if any, then, can my choice have been free?

Daniel Dennett undertakes to answer this question decisively in this engaging and very smart book. As in his previous books, about the nature of consciousness and the implications of Darwin's work, for example, he has rendered the difficult comprehensible and has ably defended a clear piece of intellectual territory. If a main aim of philosophy is the clarification of discourse, then Dennett is extremely good at his trade.

He is part of a growing group of philoso-

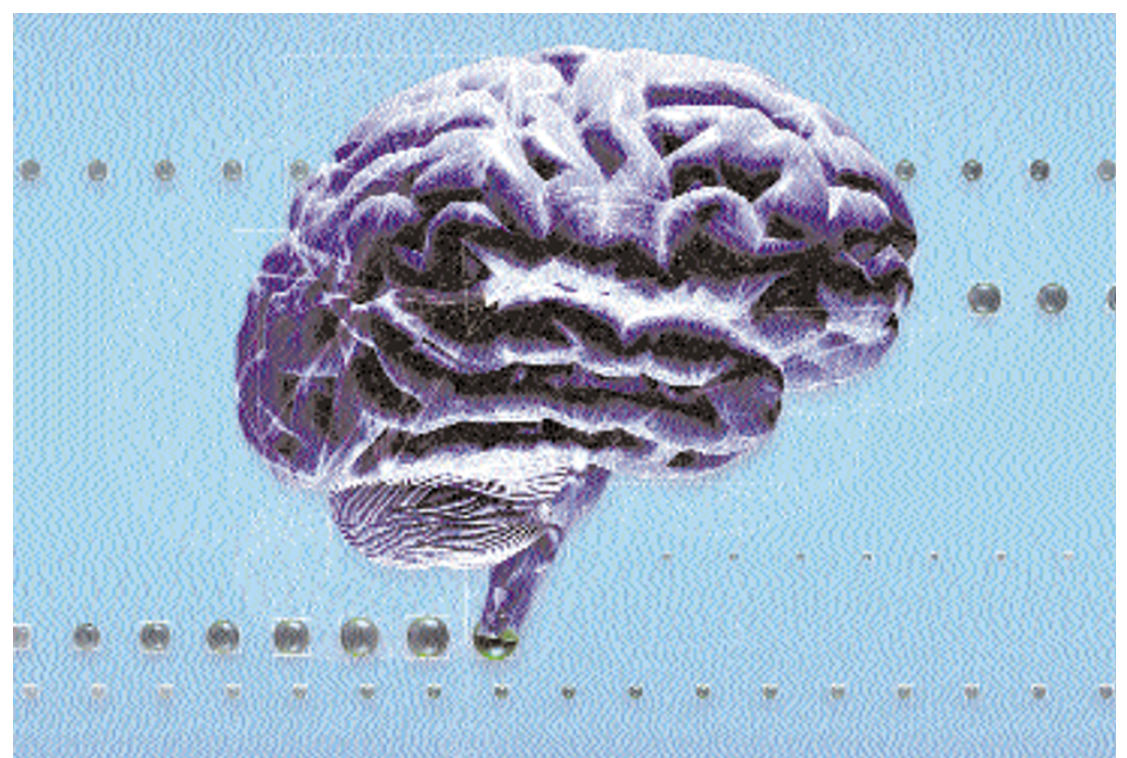

Free thinking? Decisions made in the brain are at the end of a causal chain going back to the Big Bang.

phers, beginning with David Hume in the eighteenth century (although Aristotle had related leanings), who believe that they must understand science. They believe this not because they think that empirical facts drive philosophy, nor because they want scientists to lead them around by the nose, but because they think the most profound argument cannot stand unless it is consistent with the facts, and science is the best way to discover facts.

Dennett eliminates certain old arguments about the mind by demonstrating their incompatibility with facts: for instance, that neural circuits are the entire basis of consciousness; that there is no cartesian theatre in the brain; and that evolution explains all of life, including ourselves and our moral choices. But here his goal is more specific and grander. He proposes to show not only that such facts are no threat to free will, but that they positively enhance it.

I can't do justice to his claims here, but I did not find them convincing. In brief, he takes the position that free will and determinism are compatible, and that those who think they must relinquish one or the other are yielding to a merely imagined constraint. But most of the book consists of conventional arguments in favour of determinism itself, which alone cannot support his view.

It is true, for example, that the mind is not separate from the brain, but this fact cannot enhance free will. It is true that evolution has enlarged our freedom of choice; "free as a bird" is lovely but is no compliment to a person who has at her disposal the power of culture and history. Yet such a person, like the bird, is constrained by genes, habits, energy, gravity and other forces. It is true that psychologists can easily insert false beliefs into decisions, and that conscious choices are temporally smeared or spread out in the brain, but how do these facts free us? No one denies that we are unique in the animal world in raising these questions, but do we do so by choice? The puzzle of free will, I think, remains unsolved.

Nevertheless, the book is wonderfully interesting. Scientists may know many of the themes covered here - the Life game's simulation of evolution, the nature of neuralnetwork models, the blindness of natural selection - but they may be news to some philosophers, who will need to grapple with their implications. As for the general reader, and I hope there will be many, the book is a succession of powerful ideas explained in lively and highly original ways.

Dennett's demolition of bad arguments is entertaining. The philosopher John Austin argued that, while he kicked himself for not having made a golf putt, under those exact conditions he could not have done better. Dennett counters that what we mean by "I might have done it" refers not to those exact conditions but to a set of roughly similar conditions. Robert Kane advanced a theory of "self-forming actions", occurring at critical junctures in life when our choice is not determined - breaks in the causal chain. But why would those choices escape causation more than any other?

Yet there are, I think, two partial refuges for free will at the end of the causal chain of 
evolutionary, genetic, developmental, environmental and neural determinants. The first is that this chain is almost completely unknowable. There are so many steps, each of which is so sensitive to initial conditions (defined at any arbitrary starting point) that a computer the size of the Universe, with as many transistors as there are quarks, and all the time remaining until entropy reigns could not predict more than probabilistically the simplest human decision.

The second refuge is more important. My mind may be a survival machine with predetermined choices, but I live inside it. I can embrace the facts of neurobiology, while rejecting the notion of using it to convey my subjective experience. "I was walking on a dark street and the central nucleus of my amygdala reported signals to the basolateral nucleus." No. "I was afraid." You immediately know what I mean because you have been afraid, and the unique human capacity for language-based intersubjectivity allows you to understand me.

I experience choice the way I experience fear, and you experience my choices - praising some, punishing others - as you experience my fear. It is simply a misuse of language to say that the causal chain threatens freedom, because what we mean by free will is part of our subjective experience. We may be Lumina's children, but she does not control our choices, because what we mean by 'choice' is not freedom from the causal chain; it is our insider's view of one link, as vital and inexplicable as fear, joy or love. I trust that you will hold me responsible for my choices, regardless (with few exceptions) of their many unknown causes. We live, you and I, in a subjective world of choices, and that is all we really need to know about free will.

Melvin Konner is in the Department of

Anthropology, Emory University, Atlanta, Georgia 30322, USA. He is the author of the revised edition of The Tangled Wing: Biological Constraints on the Human Spirit.

\section{Secrets of the tomb}

The Scientific Study of Mummies

by Arthur C. Aufderheide

Cambridge University Press: 2003. 626 pp.

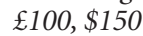

\section{Sarah U. Wisseman}

The esoteric discipline of mummy studies has come a long way in the past 30 years. In the 1970s, scientific teams at Manchester Museum in Britain and the University of Pennsylvania in the United States undertook major projects that included full autopsies of Egyptian mummies, gaining valuable information about lung and heart diseases, dental

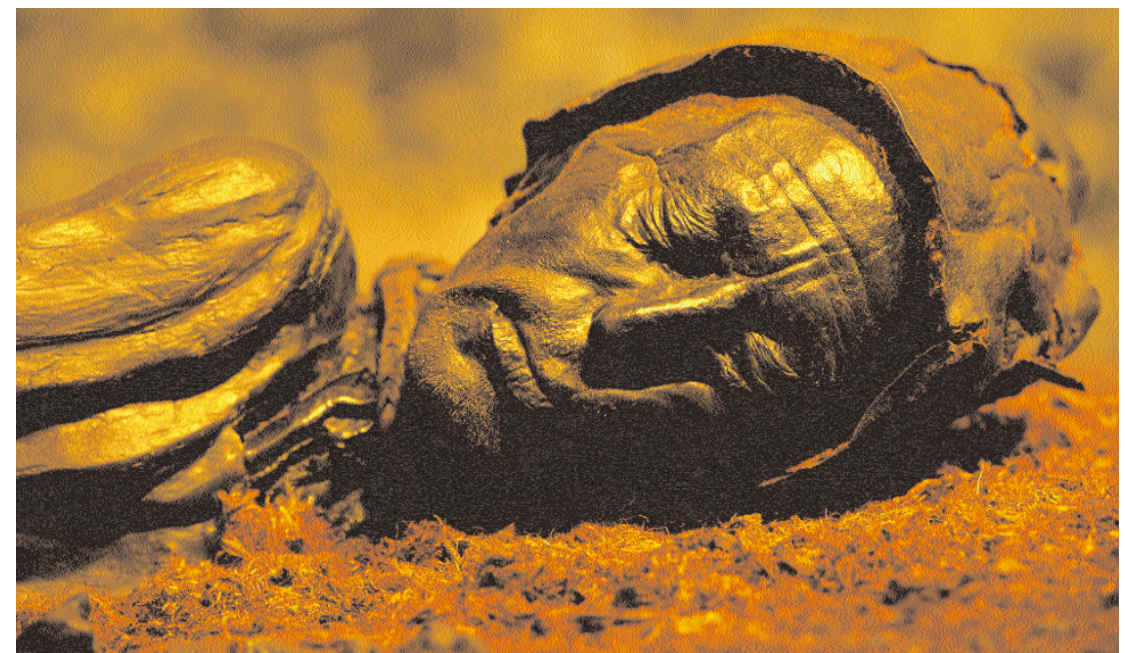

The mummy returns: the remains of Tollund Man were unearthed after 2,000 years in a Danish bog.

health and intestinal parasites, as well as the fabrics and fluids used by the embalmers. Needless to say, the subjects of these autopsies lost their value as museum display objects. Non-invasive techniques, such as $\mathrm{X}$-ray radiography and computed tomography (CT), have subsequently been used to achieve some of the same objectives without harming the exterior of the mummies.

The Scientific Study of Mummies is a veritable encyclopaedia of mummies and of mummy-research projects. Arthur C. Aufderheide is uniquely equipped to write such a book, having personally dissected more than 500 mummies. First he sets the stage with the history, purpose and mechanisms of mummification. Then he takes us on a world tour of mummies, ranging from the Americas (including the Peruvian Ice Maiden and a spontaneously mummified woman dubbed Miss Chile) to Europe (the Alpine iceman and Danish bog bodies, along with many less-well-known mummies), the Canary Islands (home of the Guanche mummies and the site of the First World Congress on Mummy Studies in 1992), Egypt, China, Japan, Australia and New Zealand.

The second half of the book reads almost like a medical text and assumes a basicknowledge of chemistry. The section on the softtissue taphonomy of mummies, defined by the author as "the effects of postmortem processes that altered the decay mechanism sufficiently to result in mummification", is quite technical, but is clearly presented with ample illustrations. This discussion features numerous agents that cause decay and deterioration: water, bacteria, fungi and temperature fluctuations. Aufderheide then describes the full range of invasive and noninvasive research methods that have been used by mummy researchers, from dissection and tissue sampling to radiology, electron microscopy, endoscopy and magnetic resonance imaging (to be successful, the last technique usually requires the rehydration of the mummy tissues). In the palaeopathology section, we learn about the diseases and abnormalities that afflicted ancient as well as modern humans: everything from ear infections to silicosis. Lung tissue is often better preserved than other parts of the body, so there is more information on lung diseases than on other types. The author also describes the parasites found in mummies, such as the fish tapeworm that infected people who ate uncooked fish. As he notes: "the biomedical data these mummies supply tells us how the diseases we presently suffer have evolved".

The author's training as a pathologist is reflected in his content and emphases. His discussion of Egyptian mummification chronology stresses the physical aspects of the mummies rather than their historical contexts. Cross-comparison of materials used in embalming, arm and leg positions, packing and organ removal are useful in understanding the range of practices over time, but no chronology can be complete without the archaeological context (such as site and tomb if known, region and circumstances of recovery). Another problem, as Aufderheide himself points out, is that the data he uses range from observations made 100 years ago to recent work. One must also take into account the changes in imaging resolution over time; our view of many mummies would benefit from re-examination by modern X-rays and CT scans.

The extensive bibliography includes both medical and archaeological references. A glossary of technical terms would have been helpful, particularly for those without training in the biological sciences. Nonetheless, this book should be required reading for any serious researcher on the sometimes gory but always fascinating subject of mummies and what they can teach us about human beliefs and behaviour.

Sarah Wisseman is in the Program on Ancient

Technologies and Archaeological Materials,University of Illinois, Urbana-Champaign, Illinois 61801, USA. 